\title{
Joint Probability Prediction Model of Rainfall Triggered Landslides and Debris Flows
}

\author{
Guilin Liu, Defu Liu*, Tianfu Li, Fengqing Wang, Tao Zou \\ Disaster Prevention Research Institute, Ocean University of China, Qingdao, China \\ Email: \{liuguilin73, "*liu, \}@ouc.edu.cn, streamlee111@yahoo.com.cn, \\ wang_qd1936@yahoo.cn, zt_dream@163.com
}

Received February 6, 2012; revised March 6, 2012; accepted April 1, 2012

\begin{abstract}
The rainfall induced landslides and debris flows are the major disasters in China, as well in Europe, South America, Japan and Australia. This paper proposes a new type of joint probability prediction model—Double Layer Nested Multivariate Compound Extreme Value Distribution (DLNMCEVD) to predict landslides and debris flows triggered by rainfall. The outer layer of DLNMCEVD is predicting the joint probabilities of different combinations for rainfall characteristics, air temperature and humidity, which should be considered as external load factors with geological and geotechnical characteristics as resistance factors for reliability analysis of slope stability in the inner layer of model. For the reliability and consequence analysis of rainfall-induced slope failure, the Global Uncertainty Analysis and Global Sensitivity Analysis (GUA \& GSA) should be taken into account for input-output iterations. Finally, based on the statistics prediction by DLNMCEVD, the geological hazards prevention alarm and regionalization can be provided in this paper.
\end{abstract}

Keywords: Prediction; Rainfall; Landslides and Debris Flows; DLNMCEVD; GUA \& GSA

\section{Introduction}

The rainfall-induced landslides and debris flows are the major disasters in South American, Europe as well as in China due to the following facts:

The climate of South American, some European counties and China mainly possess the features of hurricane/ typhoon/tropical cyclone, monsoon type and precipitation is concentrated in summer, forming stormy rainfall which is the main inducing factor for landslide and debris flow.

The resident in mountainous area mainly distributes along valleys on river terraces, diluvia fans and taluses. The land reclamation often leads to soil erosion and slope failure which threaten the safety of life and property.

Highway and railway in mountainous area are mostly arranged along river valley and gulley and often constructed by slope cutting, by which the stability condition of natural slopes is disturbed. Slope collapse, landslides and debris flows influence the traffic and threaten the life safety.

The construction of hydro-power stations, nuclear power plants and mines, new resettle regions, slope cutting, earth filling and waste piling have destroyed the primary land form; the ground water extraction and waste water infiltration change the original groundwater

*Corresponding author. condition. All these changes of natural conditions can lead to the change of slope stability.

Due to the above mentioned reasons, the rainfall induced landslides and debris flows should be investigated further.

Since the geological environment and the geotechnical characteristics are complicated and changeable, the rainfall-induced landslide and debris flow possess localized features and complicated types. In the world wide the study of slope stability is concentrated in slope classification, failure mechanism, failure mode, investigation techniques, method of stability analysis, monitoring techniques and treatment measures [1]. During these studies the rainfall is treated as an acting factor to the slope stability. The study on regional features of slope is especially lack, which is more important for development planning, earth use planning and risk management.

The study on rainfall-induced slope failures is more developed in a few countries, such as Italy of Europe, Hong Kong District of PRC, Japan, and Australia [2]. However the study in this countries or districts mainly is performed in combination with the study on certain slope or landslide, so the approaches vary from pure statistics to mechanical analysis. Among these studies only the landslides in Hong Kong are predicted and assessed by using the rainfall as the only indicator. With developed economy and dense population, landslide in Hong Kong 
may cause higher risks; therefore, the government pays great attention to the study of landslide. The geological and geo-morphological conditions and the slope failure low have been studied in detail since the territory of Hong Kong is small, and the slope movement and the rainfall are monitored by a net equipped with automatic apparatus. On this basis the correlation of slope failure with rainfall could be established.

In China, the local authorities and the large industrial or construction units pay more attention to the monitoring and treatment of certain slopes but the correlation between rainfall and happening of landslide or debris flow is less investigated. In the mainland of China the study on distribution of landslides in some area is well carried out. For example there is a scientific work "Landslides in Gansu Province", one of the results of which is the landslide hazard map for East Gansu based on geomorphology, geology and past landslide activity. This map has been used as basic guideline in land-use planning. However the study on correlation between the landslide and the rainfall is still very rough. Since the lack of such scientific investigation, errors in development planning or land usage planning for new constructed or extended area are frequently have made. For example, there are many building damages due to creep, deformation or tension cracks in foundation induced by the first rainfall after the completion of a new resettle point. However if this area was planned for a square or a traffic line, the loss would be less or even be avoided. Another example, there was an accident of powerhouse inundation of a hydropower station by a debris flow induced by an extra storm rainfall, since during construction the constructor has piled the solid waste in a gulley just located at the upstream of the power house [3]. For the landslides prevention the national design code was established [4]. As the important triggering factor for landslides and debris flow in 16 coastal and inland provinces of China typhoon induced storms and flood and its probability model was studied [5].

Targets of the study are focused on scheme of zoning of a certain region according to the relative homogeneity of the geological and geo-morphological conditions as well as the similarity of the failure mechanism and failure type of slopes and establish a theoretically based and practically applicable joint probability prediction model for rainfall induced landslides and debris flows.

\section{Scheme Rainfall-Induced Landslides and Debris Flows Disasters Zoning}

In case that the possibility model is used for prediction and assessment of rainfall-induced landslides and debris flows in a large area, the condition of occurrence of these disasters and the similarity of their mechanism should be taken into consideration. Under different geological and geo-morphological conditions a rainfall with a same intensity, a same prolonged time and a same accumulate precipitation may result in an inducing event or a noninducing event; in case of an inducing event, disasters of landslide or debris flow with different degrees may take place. In view of these facts we must discuss the mechanism of the rainfall-induced disasters and a necessary simplified treatment should be made.

\subsection{Slope Type and the Stability Situation}

For the study of slope failures induced by rainfall the slopes should be classified at first into rock slopes and earth (including unconsolidated materials) slopes. The reasons are: 1) The people living in mountainous and hilly regions is mainly settled along river valley on the terraces, diluvia fans and taluses, slopes in which can be distinguished as earth slopes; 2) the slopes in the sites of large hydro-power stations, strip mines and along main traffic lines are mainly rock slopes.

1) Earth slopes

The infiltration of rain water changes the physical situation of earth. Under the natural moisture situation earth exists in a solid or hard-plastic state. With the increasing of moisture content resulted from infiltration during rainfall earth turns into a soft-plastic state or even to a flow state. So the failure of an earth slope starts from creep to slump or to plastic flow and finally evolves to a mud flow or debris flow.

This failure mode is fit to slopes composed of earth mixed with rock fragments in natural deposits, such as slope wash, talus, residual slides in mountainous and hilly region or man-made fills, as well as to slopes composed of homogeneous soil.

\section{2) Rock slope}

The infiltration of rain water imparts pore-water pressure in rock mass, reduces the shear strength of the discontinuities in rock mass, especially of the weak structure planes, and induces landslide. The strength reducing is less important in wet area of heavy rainfall since the moisture content of weak structure planes in rock mass are near to saturation; the main role is increased water pressure.

Rock-slides are almost exclusively conditioned by discontinuities dipping outwards. A storm rainfall may induce rock fall in superficial highly weathered rock.

3) Stability situation of slope [6]

Since slope failure is a process of losing stability, certain stability situation of a slope should be defined in accordance with its developing stage. In Appendix A of the Design Specification for Slope of Hydropower and Water Conservancy Project of PRC [5,7,8] slopes are classified in to stable, potentially unstable, deforming, unstable and post-failure slopes according to there stability situation. For instance, slopes in an area where land- 
slide frequently occurs are mostly in deforming or potentially unstable situation while rock slopes in an arid area are mostly in long term stable situation.

\subsection{Secondary Disasters Induced by Human Activities}

Human activities often break the natural balance of slopes, making the slope stability worse, decreasing the threshold value of inducing rainfall and increasing the probability of slope failure. Many landslides and debris flows are induced by construction of highway or railway and distribute along traffic lines. The factor of human activity should be considered in zoning of a region as well as in determination of rainfall threshold values. The secondary disasters brought by human activities are mainly as follows:

Engineering cutting steepness slopes or undercuts rock slopes at their toes making the slip surface daylight at slope surface. The examples of these situations are slopes along highway or railway, slopes at rock quarries and open-pit mines.

The waste water infiltrates into ground raising the ground water table and decreasing the stability of slope. This situation is often met in new resettlement area for reservoir immigrant or in newly constructed or extended town.

Damage of natural vegetation leads to soil erosion, for example, along traffic lines or in construction sites.

Piling of waste solid obstructs the discharge channel. For example, the waste rock and earth materials are piled in gulley inducing debris flow in rainy season.

The secondary disasters may be induced by hydraulic works. For example, water leakage from diversion tunnel, rapid drawdown of river or reservoir water level and artificial rainfall induced by flood discharge during rainy season may induce landslides along river banks.

\section{The Double Layer Nested Multivariate Compound Extreme Value Distribution (DLNMCEVD) and Its Application to Prediction of Rainfall-Induced Landslides and Debris Flows}

The DLNMCEVD model is developed based on theory of "Multivariate Compound Extreme Value Distribution" (MCEVD), which is compounding a discrete distribution with a multivariate joint probability distribution [9-11].

MCEVD was firstly published in USA as form of Compound Extreme Value Distribution (CEVD) for typhoon disaster prediction [12] and applied in long term prediction of hurricane Characteristics along US Gulf and Atlantic sea areas in which the hurricane central pressure predicted by CEVD and NOAA (National Oceanic \& Atmospheric Administration) was shown in Fig- ure 1 [13]. The comparison shows the significant differences between CEVD and NOAA predicted results in Gulf east area A and east Florida area 1 [14], where CEVD predicted $50 \mathrm{yr}$ and $1000 \mathrm{yr}$ return period hurricane intensity much more severe than NOAA proposed SPH (Standard Project Hurricane) and PMH (Probable Maximum Hurricane) respectively. 2005 hurricane Katrina and Rita attached mentioned above areas and brought 2000 deaths, 4000 million US\$ in New Orleans and 110 offshore platforms collapsed. The SPH was used as design criteria for New Orleans defense structures and lead to historical severest disasters in USA [15-17]. Table 1 shows the comparison between CEVD, NOAA predicted results and hurricane Katrina and Rita data.

Many application of MCEVD in engineering design and risk analysis show the scientific and reasonable of its predicted results in China and abroad [18-23]. As mentioned in "Summary of flood frequency analysis in the United States" [18]: "The combination of the eventbased and joint probability approaches promises to yield significantly improved descriptions of the probability laws of extraordinary floods". MCEVD is the model which follows the development direction of the extraordinary floods prediction hoped for by Kirby and Moss. Since 2005 hurricane Katrina and Rita disasters proved accuracy of 1982 predicted hurricane characteristics and after disaster calculated results. It stands to reason that

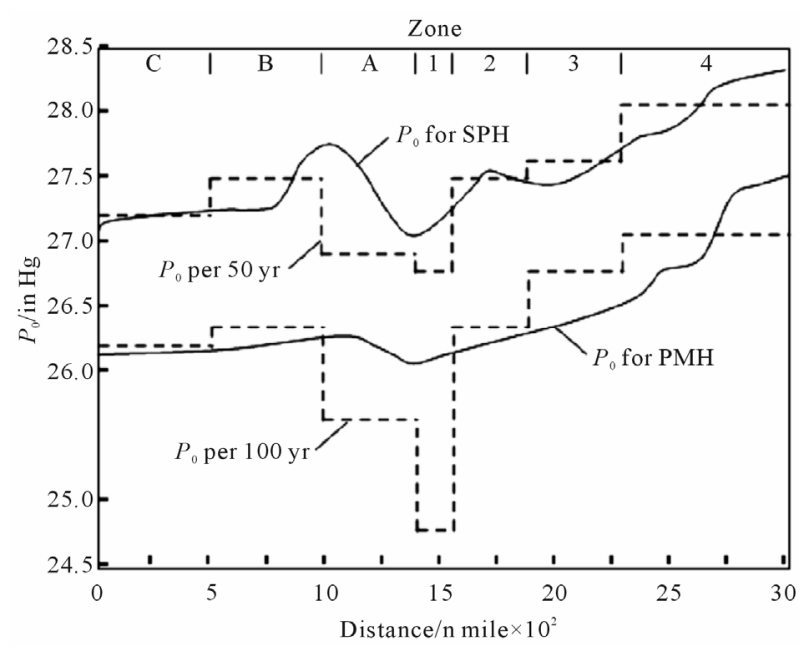

Figure 1. Comparison between the results of CEVD and NOAA (10, figure 6).

Table 1. Comparison between NOAA and CEVD.

\begin{tabular}{cccccc}
\hline \multirow{2}{*}{ Zone } & \multicolumn{2}{c}{ NOAA $(\mathrm{hPa})$} & \multicolumn{2}{c}{ CEVD $(\mathrm{hPa})$} & Hurricane $(\mathrm{hPa})$ \\
\hline \multirow{2}{*}{$\mathrm{A}$} & SPH & 941.0 & $50-\mathrm{yr}$ & 910.8 & Katrina \\
& PMH & 890.5 & $1000-\mathrm{yr}$ & 866.8 & 902.0 \\
\multirow{2}{*}{1} & SPH & 919.3 & $50-\mathrm{yr}$ & 904.0 & Rita \\
& PMH & 885.4 & $1000-\mathrm{yr}$ & 832.9 & 894.9 \\
\hline
\end{tabular}


MCEVD is a practicable model for prediction of typhoon/hurricane/tropical cyclone induced extreme events. Our proposed methods in [10-13] are used as design criteria of wind-structure interaction experimentation for mitigating hurricane-induced coastal disasters in US [19].

\section{Dewrivation of PNLTCED}

As mentioned above, the frequency of extreme events occurrence (typhoon, hurricane, tropical cyclone or winter storm) can be fitted to Poisson distribution

$$
P_{i}=\frac{e^{-\lambda} \lambda^{i}}{i !}
$$

where $\lambda$ is the mean value of the extreme events occurrence per year.

The PNLTCED can be obtained as

$$
\begin{gathered}
F\left(x_{1}, x_{2}, x_{3}\right) \\
=\exp \left[-\left\{\left[1+\xi_{1} \frac{x_{1}-\mu_{1}}{\sigma_{1}}\right)^{\frac{-1}{\alpha \beta \xi_{1}}}+\left(1+\xi_{2} \frac{x_{2}-\mu_{2}}{\sigma_{2}}\right)^{\frac{-1}{\alpha \beta \xi_{2}}}\right]^{\beta}\right. \\
\left.\left.+\left(1+\xi_{3} \frac{x_{3}-\mu_{3}}{\sigma_{3}}\right)^{\frac{-1}{\alpha \xi_{3}}}\right\}\right] \\
f\left(x_{1}, x_{2}, x_{3}\right)=\frac{\partial^{3} F\left(x_{1}, x_{2}, x_{3}\right)}{\partial x_{1} \partial x_{2} \partial x_{3}}
\end{gathered}
$$

in which $\xi_{j}, \mu_{j}, \sigma_{j}$ are the shape, location and scale parameters of marginal distributions $F\left(x_{j}\right)$ to $x_{j} \quad(j=$ $1,2,3)$, respectively. And dependent parameters $\alpha, \beta$ can be obtained through moment estimation

$$
\begin{aligned}
& \hat{\alpha}=\frac{\sqrt{1-r_{13}}+\sqrt{1-r_{23}}}{2} \\
& \hat{\beta}=\frac{\sqrt{1-r_{12}}}{\hat{\alpha}}
\end{aligned}
$$

where $r_{i, j}$ is correlation coefficient, $i<j, i, j=1,2,3$.

Tri-variate layer structure ( $\alpha$-outside, $\beta$-inside layer) shows that the correlation between $x_{1}$ and $x_{2}$ is stronger than those among $x_{1}, x_{3}$ and $x_{2}, x_{3}$.

According to the stochastic simulation method for the test of CEVD and importance sampling procedure using design point (ISPUD) [24], a new type of stochastic simulation procedure based on MCEVD-Poisson-ISPUD (P-ISP) is developed, which can be used in the multivariate joint probability analysis of annual typhoon frequency and other six typhoon characteristics [25]. In the simulation procedure, it is needed to input the mean value of typhoon frequency $(\lambda)$, marginal distribution of the six kinds of typhoon characteristics (P-ISP is suitable for different kinds of distributions, such as normal, uniform, exponential, Rayleigh, Gumbel, Weibull, log-normal, Gamma Frechet distributions, and so on), the mean value and standard deviation of each variable group, matrix correlation coefficients among the variables and the limit state equation. Then the joint probability of different typhoon characteristics with some typhoon occurrence frequency can be calculated as the output. Comparing with the basic Monte Carlo method, P-ISP performs more quickly and accurately, so it has been successfully applied to the joint probability analysis of typhoon induced extreme sea environmental loads such as wind, wave storm surge, current, rainfall, etc., also to different kinds of offshore engineering structures, risk assessment of fixed platform, coastal defense for Nuclear Power Plant, hydraulic structures of Olympic sailing games and design floods [26-30]. It should be noticed that the solution of the multi-dimensional joint probability problem is a contour surface with some probability value. In applications, aiming at different objectives, for instance, $\Delta P$ reflects typhoon intensity, $R_{\max }$ reflects area influenced by typhoon, $s$ reflects intensity of typhoon induced surges and waves, and $t$ reflects inland areas affected intensity, the dominated factor should be selected respectively to calculate the unique solution of the joint probability for different disaster consequences. This procedure is taken as the first layer of the double-layer nested multi-objective probability model, which offers the basis for typhoon disaster zoning.

According to the calculated results using 50-yr observed typhoon data, the marginal distributions of different typhoon characteristics of sea area of China can be described by following distributions: $\triangle P$ - Gumbel, Weibull, Log-normal; $R_{\max }$-Normal, Log-normal; $s$-Gumbel, Normal; $\delta$-Uniform, Log-normal; $\theta$-Log-noraml; $t$-Gumbel, Log-normal, Normal.

The mean value and standard deviation of each typhoon characteristic factor, and matrix correlation coefficients among the variables should be calculated for different areas.

The DLNMCEVD is combined an outer layer of climate and meteorological characters (threshold level of rainfall volume for landslides or debris flows beginning, rainfall intensity, duration, cumulative volume, air temperature and humidity) with the predicted combinations with different joint probabilities, and the geological, geotechnical factors such as ground water level, soil strength, sand grades, ... in the inner layer. Combinations of predicted climate, meteorological factors for outer layer as the loads factors and the geological, geotechnical characteristics for the inner layer as the resistance factors, the slope stability situation can be estimated by reliability analysis. The DLNMCEVD flow chart is shown in Fig- 


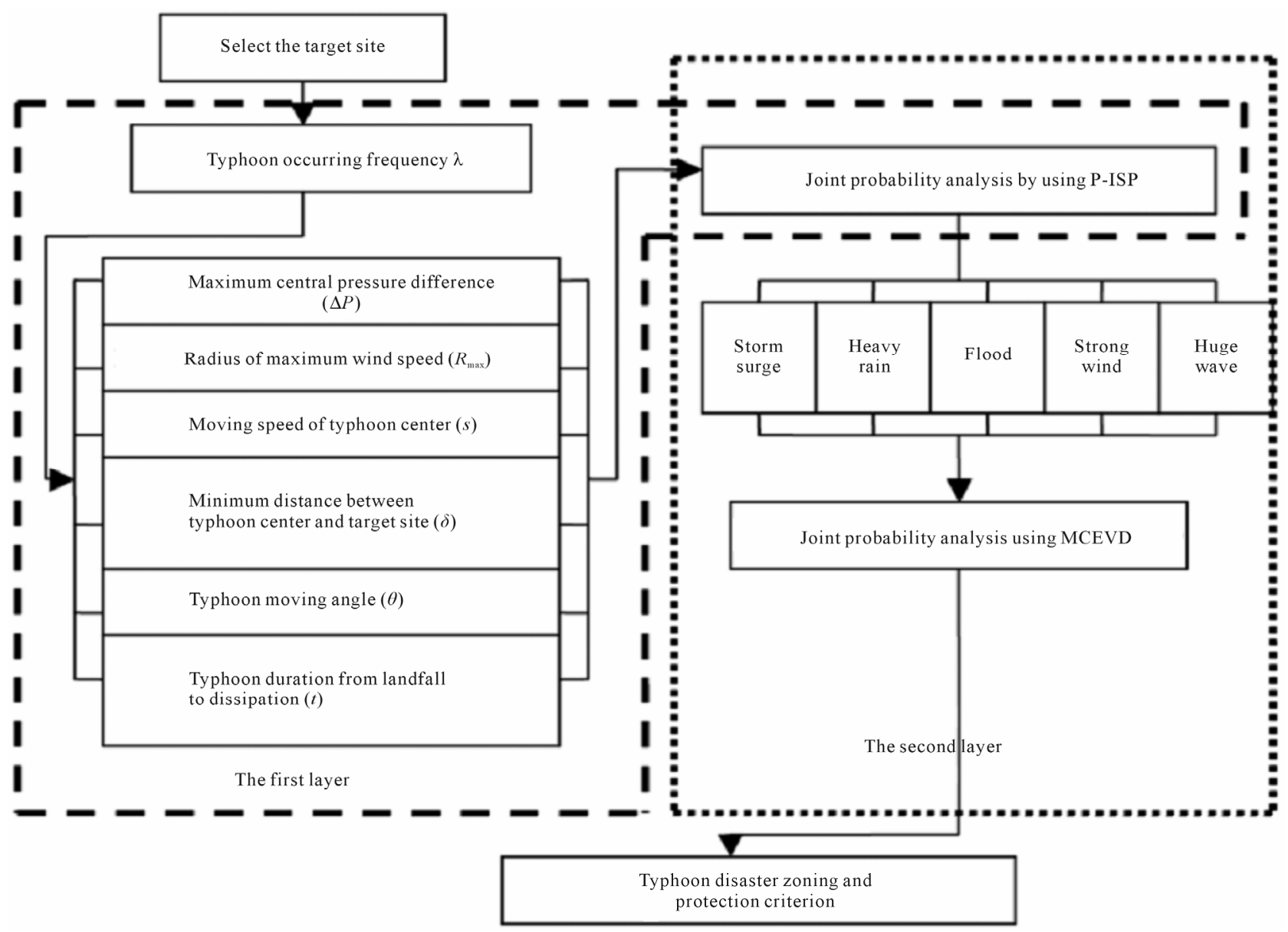

Figure 2. Double layer nested multi-objective probability model of typhoon disaster zoning and prevention criteria.

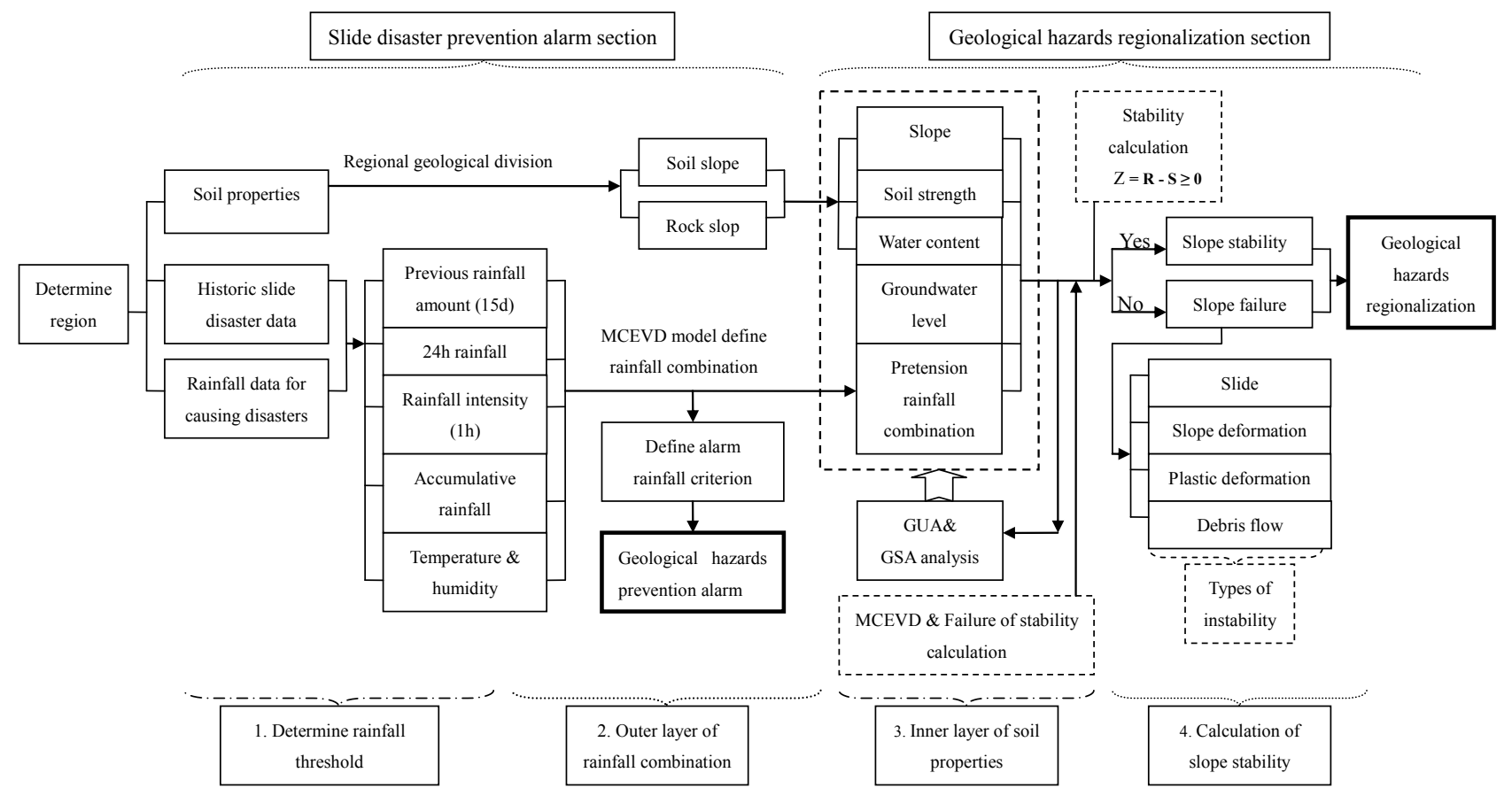

Figure 3. The float chart of DLNMCEVD application of slide disaster research. 
ure 2 , where $\lambda$ is frequency per year of rainfall volume over threshold level rainfall volume triggering landslides or debris flow in beginning state.

\section{Application GUA \& GSA for Prediction of Rainfall Induced Landslides and Debris Flow}

GUA \& GSA are useful to accomplish a number of tasks and provide guidance to improve the quality of environmental assessment practices and decision support systems employed in environmental policy, ultimately improving their reliability, transparency and credibility. For instance GUA \& GSA can help to understand whether the current state of knowledge on input data and related uncertainties is sufficient to enable a decision to be taken. If not, it helps identify which data or parameters require resources to be allocated for knowledge improvement, in order to achieve the desired level of confidence for the results [31]. For the complex input-output processes for prediction of rainfall induced landslides and debris flows the combination of uncertainty and sensitivity analysis in an iterative procedure of DLNMCEVD should be taken advantage of their complementary aspects:

1) Rainfall uncertainty

Uncertainty through the calculation of threshold level for rainfall induced landslides or debris flow in beginning state; Uncertainty of rainfall characteristics; Data sampling uncertainty.

2) Geological and geotechnical parameters uncertainties.

3) Uncertainties through the slope stability analysis.

4) Uncertainties related to human activities.

5) Based on the predicted results by DLNMCEVD in an iterative procedure the landslides and debris flow dis-
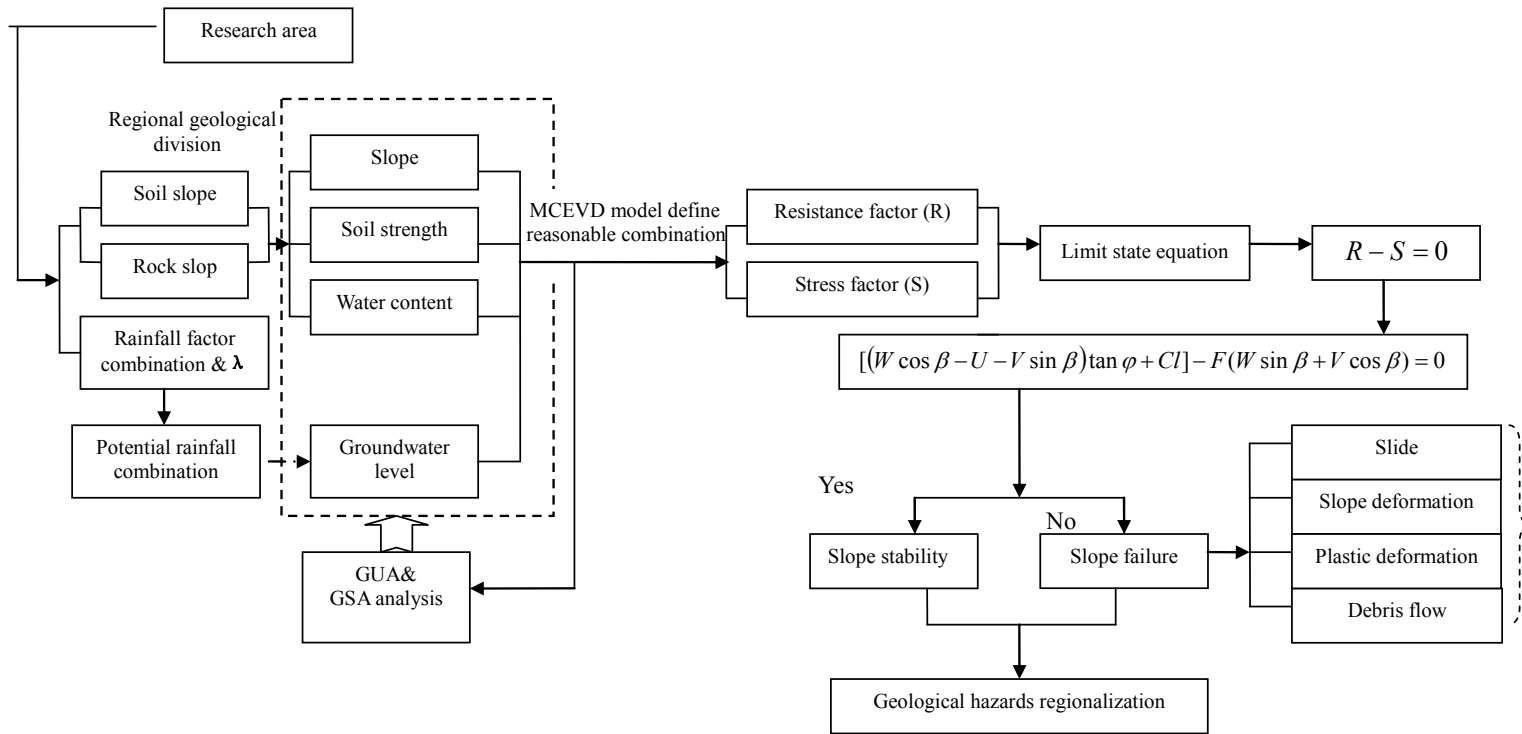

(a)

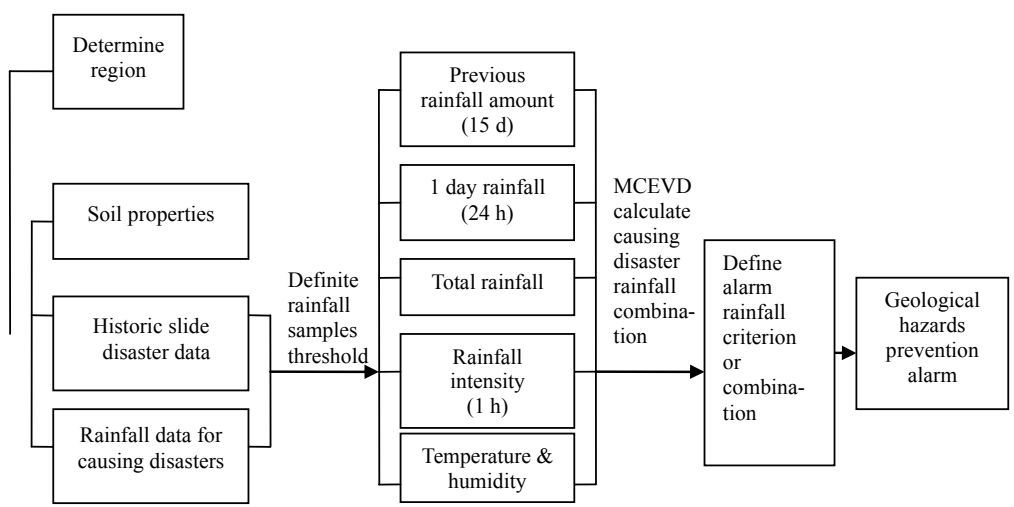

(b)

Figure 4. (a) Joint probability assessment of geo-hazards regionalization and types of instability; (b) The float chart of geological hazards prevention alarm. 
aster prevention alarm and regionalization can be provided.

The float chart of DLNMCEVD application of slide disaster research can be seen in Figure 3.

In Figure 4(a): $F$-Factor of safety; $W$-dead weight of the sliding rock mass; $\beta$-dip angle of the slide surface; $U$ water pressure acting on the slide surface; $V$-water pressure acting on the rear edge crack; $\varphi$-friction angle of the slide surface; $C$-cohesion of the slide surface; $l$-length of the slide surface.

\section{Conclusions}

The targets of the paper are focused on scheme of zoning of a certain region according to the relative homogeneity of the geological and geo-morphological conditions as well as the similarity of the failure mechanism and failure type of slopes and establish a theoretically based and practically applicable joint probability prediction model for rainfall induced landslides and debris flows. Based on the double layer nested multi-objective probability model, landslides and debris flows disasters prediction, prevention, alarm and regionalization system can be proposed. It has important practical value and will bring great economic and social benefits.

The Multivariate Compound Extreme Value Distribution and DLNMCEVD model widely used in coastal, offshore and hydraulic engineering design and safety assessment. We hope that proposed joint probability prediction model of rainfall triggered landslides and debris flows also can be used in disaster prevention and mitigation.

\section{REFERENCES}

[1] R. Fell, O. Hunger, S. Leroueil and W. Riemer, "Keynote Lecture-Geotechnical Engineering of the Stability of Natural Slopes, and Cuts and Fills in Soil," Invited Lecture, GeoEng 2000.

[2] M. Polemio and O. Petrucci, "Rainfall as a Landslide Triggering Factor: An Overview of Recent International Research," Landslides in Research, Theory and Practice, Vol. 3, 2000, p. 1219.

[3] W.-J. Wu and N.-Q. Wang, "Landslide Hazards in Gansu Province of China," Lanzhou University Publishing Company, Lanzhou, 2006.

[4] T. F. Li, et al., "Design Specification for Slope of Hydropower and Water Conservancy Project," National Development and Reform Commission, 2007.

[5] B.-T. Xie, D.-F. Liu, et al., "Statistical Prediction of Long Term Characteristics for Typhoon Induced Rainstorm and Inundation in China," Proceedings of 27th International Conference on Offshore Mechanics and Arctic Engineering, Estoril, 15-20 June 2008, pp. 19-26.

[6] T.-F. Li, et al., "The Failure Mechanism of Rock Slope with Bedding Structure," Hydropower, Vol. 1, 1996, pp.
46-49.

[7] T.-F. Li, "Treatment Targets and Design Principle for Destabilized Bank Slopes of the Three Gorges Reservoir," Northwest Water Power, Vol. 3, 2002, pp. 8-11.

[8] T.-F. Li, "On Toppling Failure of Bedded Slope," Northwest Water Power, Vol. 3, 2006, pp. 4-6.

[9] D.-F. Liu, L. Pang and B.-T. Xie, "Typhoon Disaster in China-Prediction, Prevention and Mitigation," Natural Hazards, Vol. 49, No. 3, 2009, pp. 421-436. doi:10.1007/s11069-008-9262-2

[10] D.-F. Liu, L. Pang, Y.-K. Wu and B.-T. Xie, "Typhoon Disaster Zoning and Prevention Criteria-A Double Layer Nested Multi-Objective Probability Model and Its Application," Science in China, Series E, Vol. 51, No. 7, 2008, pp. 1038-1048. doi:10.1007/s11431-008-0053-5

[11] D.-F. Liu, H.-D. Shi and L, Pang, "Disaster Prevention Design Criteria for the Estuarine Cities: New Orleans and Shanghai," Acta Oceanologica Sinica, Vol. 25, No. 4, 2006, pp. 131-142.

[12] D.-F. Liu and F.-S. Ma, "Prediction of Extreme Wave Heights and Wind Velocities," Journal of the Waterway Port Coastal and Ocean Division, Vol. 106, No. 4, 1980, pp. 469-479.

[13] D.-F. Liu, "Long Term Distributions of Hurricane Characteristics," Offshore Technology Conference, Houston, 3-6 May 1982, pp. 305-313.

[14] R. W. Schwerdt, F. P. Ho and R. R. Watking, "Meteorological Criteria for Standard Project Hurricane and Probable Maximum Hurricane Wind Fields, Gulf and East Coast of the United States," NOAA Technical Report NWS 23, 1979.

[15] Army Corps of Engineers, "History of Lake Pontchartrain and Vincinity Hurricane Protection Project," Report of US Government Accountability Office GAO-06-244T, 2005, pp. 1-4.

[16] GAO, "Lake Pontchartrain and Vicinity Hurricane Protection Project," GAO-05-1050T, Washington DC, 2005.

[17] R. Bea, "Reliability Assessment \& Management: Lessons from Hurricane Katrina," ASME 2007 26th International Conference on Offshore Mechanics and Arctic Engineering, San Diego, 10-15 June 2007, pp. 467-478.

[18] W. H. Kirby and M. E. Moss, "Summary of Flood-Frequency Analysis in the United States," Journal of Hydrology, Vol. 96, No. 1-4, 1987, pp. 5-14. doi:10.1016/0022-1694(87)90139-9

[19] A. G. Chowdhury and E. Huang, "Novel Full-Scale WindStructure Interaction Experimentation for mitigating Hurricane-Induced Coastal Disasters," Far East Journal of Ocean Research, Vol. 2, 2009, pp. 1-27.

[20] R. M. Langley and A. H. El-Shaarawi, "On the Calculation of Extreme Wave Height: A Review," Ocean Engineering, Vol. 13, No. 1, 1986, pp. 93-118. doi:10.1016/0029-8018(86)90006-5

[21] M. G. Naffa, A. M. Fanos and M. A. Elganainy, "Characteristics of Waves off the Mediterranean Coast of Egypt," Journal of Coastal Research, Vol. 7, No. 3, 1991, pp. 665-676. 
[22] S. T. Quek and H. F. Cheong, "Prediction of Extreme 3Sec Gusts Accounting for Seasonal Effects," Structure Safety, Vol. 11, No. 2, 1992, pp. 121-129. doi:10.1016/0167-4730(92)90004-7

[23] M. K. Ochi, "Stochastic Analysis and Probabilistic Prediction of Random Seas," Advanced Hydrologic, Vol. 13, 1982, pp. 5-14.

[24] U. Bourgund, W. Ouypornprasert and P. H. W. Prenninger, "Advanced Simulation Methods for the Estimation of Systems Reliability," Internal Working Report No. 19, Institution of Mechanical Engineers, University of Innsbruck, Innsbruck, 1986.

[25] L. Pang, D.-F. Liu and Y.-F. Yu, "Improved Stochastic Simulation Technique and Its Application to the Multivariate Probability Analysis of Typhoon Disaster," Proceedings of the 17th International Offshore and Polar Engineering, Portugal, 1-6 January 2007, pp. 1800-1805.

[26] D.-F. Liu, L. Pang, G. Fu and H.-D. Shi, "Joint Probability Analysis of Hurricane Katrina 2005," Proceedings of the International Offshore and Polar Engineering Conference, San Francisco, Vol. 3, 2006, pp. 74-80.

[27] D.-F. Liu, B,-T. Xie and H.-J. Li, "Study on the Flood Volume of the Three Gorges Dam Project," Journal of
Hydrologic Engineering, Vol. 16, No. 1, 2011, pp. 71-80. doi:10.1061/(ASCE)HE.1943-5584.0000287

[28] D.-F. Liu, H.-J. Li, G.-L. Liu and F.-Q. Wang, "Design Code Calibration of Offshore, Coastal and Hydraulic Energy Development Infrastructures, World Science and Engineering Academy Society (WSEAS) International Journal of Energy and Environment, Vol. 5, No. 6, 2011, pp. 733-747.

[29] D.-F. Liu, G.-L. Liu, H.-J. Li and F.-Q. Wang, "Risk Assessment of Coastal Defense against Typhoon Attacks for Nuclear Power Plant in China," Proceedings of ICAPP 2011, Nice, 2-6 May 2011, pp. 2484-2492.

[30] D.-F. Liu, Y.-P. Jiang and H.-D. Shi, "Uncertainty Analysis of Breakwater Wave Overtopping Volume, Wave Forces and Structure Stability," Proceedings of the International Offshore and Polar Engineering Conference, San Francisco, 28 May-2 June 2006.

[31] S. Tarantola, N. Giglioli, N. J. Jesinghaus and A. Saltelli, "Can Global Sensitivity Analysis Steer the Implementation of Models for Environmental Assessments and Decision-Making?" Stochastic Environmental Research and Risk Assessment, Vol. 16, No. 1, 2002, pp. 63-76. 